\title{
THE DETERMINATION OF PHOSPHORIC ACID IN MINERAL PHOSPHATES.
}

\author{
By GUNNER JÖRGENSEN.
}

In previous communications (Det Kgl. Danske Videnska. Selskabs Skrifter, 7, Rakke; Naturvidenska. og mathemat. Afdeling, 1905, 2, 4 ; Zeit. für Anal. Chem., 1906, 45, 273 ; ibid., 1907, 46, 370) I have discussed at some length the molybdic, the magnesia, and the citrate methods for the determination of phosphoric acid, and referred to other methods which from time to time have been proposed.

Working with pure sodium ammonium phosphate, I showed (loc. cit.) that the composition of the magnesium ammonium phosphate precipitated at the ordinary temperature varies with the conditions of precipitation. This is the case also with the molybdic and the citrate processes. The composition of the magnesium ammonium phosphate approaches the theoretical with an exactness of about $1: 1000$, provided that the magnesia solution is added slowly, with vigorous agitation, to the nearly boiling solution. The precipitate settles in a compact and crystalline form, but this characteristic appearance cannot be regarded as a proof of its correct composition. Since my method has now become the official one in Denmark for the analysis of fertilisers and mineral phosphates, and as there have been occasional misunderstandings concerning the precise procedure to be followed, I believe it will be useful to give a detailed description, as hitherto the method has only been described in general terms.

\section{Preparation of the Reagents.}

(a) Molybdic Solution.-One hundred grms. of pure ammonium molybdate are dissolved in 280 c.c. of ammonia (sp. gr. 0.97), and 300 c.c. of this solution are poured, with vigorous shaking, into 700 c.c. of nitric acid (sp. gr. 1-21), and the mixture allowed to stand for twenty-four hours. The ammonia solution may be prepared by mixing 84 c.c. of ammonia (sp. gr. 0.91 ) with 196 c.c. of water, and the nitric acid by mixing the strong acid (sp. gr. 1.4) with about an equal volume of water.

(b) Acid Ammonium Nitrate Solution.-This is to contain 40 grms. of ammonium nitrate and $10 \mathrm{grms}$. of nitric acid per litre. It is prepared by mixing 90 c.c. of nitric acid (sp. gr. 1.4) with about 1,500 c.c. of water, adding 80 c.c. of ammonia (sp. gr. 0.91 ), and making up to a volume of 2,000 c.c.

(c) Magnesia Solution.-Fifty grms. of pure magnesium chloride $\left(\mathrm{MgCl}_{2}+6 \mathrm{H}_{2} \mathrm{O}\right)$ and 150 grms. of pure ammonium chloride are dissolved in water, and the solution made up to 1,000 c.c.

Method.-1. Five grms. of mineral phosphate are placed in a 250-c.c. flask, and dissolved with gentle ebullition in 20 c.c. of nitric acid (sp. gr. 1.21). Solution will be complete in about fifteen minutes. The contents of the flask are cooled, made up to 250 c.c., and filtered.

2. To 50 c.c. of the filtrate contained in a beaker flask (250 c.c.) are added 165 c.c. of the molybdic solution, and the flask and its contents placed in a water-bath at a temperature of $50^{\circ} \mathrm{C}$. for ten minutes, and occasionally stirred. When quite 
cold the contents of the flask are filtered, and the precipitate washed ten times by decantation with acid ammonium nitrate solution, about 20 c.c. being used for each washing. If necessary, the filtrate may be tested for unprecipitated phosphate by adding more molybdic solution, warming up to $50^{\circ} \mathrm{C}$., and standing for twelve hours. The estimation of calcium may be proceeded with by adding a little sulphuric acid and twice the volume of the washings of alcohol.

3 . The washed molybdic precipitate is dissolved in 100 c.c. of 2.5 per cent. ammonia solution, filtered, if necessary, through the same filter which held the molybdic precipitate, the filter being washed eight times with about 10 c.c. each time of the ammonia solution, so that the final volume is about 180 c.c.

4. The beaker-flask is covered with a clock-glass, the contents brought just to the boiling-point, removed from the burner, and 30 to 35 c.c. of the magnesia solution added drop by drop from a burette, the whole being well stirred. The beaker-flask is recovered, and so long as the liquid remains very warm it is stirred frequently, and if the precipitate is not compact and crystalline the stirring should be continuous. After standing for at least four hours the solution is filtered on to a platinum crucible packed with spongy platinum, the precipitate washed with 2.5 per cent. ammonia solution until free from chlorides, and then once with alcohol.

5. The precipitate is dried and heated gradually over an Argand burner, then ignited strongly, cooled, and weighed.

Remarks. - I find that nitric acid is a convenient solvent for ordinary mineral phosphate, as the presence of the small amount of silica does not interfere with the accuracy of the method. If large amounts of organic matter are present, a more energetic solvent should be used. The elementary precaution that the pipette and 250-c.c. flask should correspond with each other must not be overlooked. The amounts of molybdic and magnesia given alone are sufficient even if the mineral phosphate contained 100 per cent. calcium phosphate. The excess of molybdic solution is smaller than is usually employed in other methods, and the chance of the precipitation of arsenic or silica is thereby diminished. It should be borne in mind that by a prolonged standing the strength of the molybdic solution may be lessened by the separation of molybdic acid. Too long a boiling before the precipitation with the magnesia solution should be avoided, as the consequent loss of ammonia will result in an incomplete precipitation of magnesium ammonium phosphate.

In the analysis of artificial manures the undermentioned quantities of reagents are used:

\begin{tabular}{|c|c|c|c|c|c|c|c|}
\hline \multirow{2}{*}{\multicolumn{2}{|c|}{ Molybdic solution }} & \multicolumn{3}{|c|}{$\begin{array}{l}\text { For } 50 \text { c.c. of an Aqueous } \\
\text { Extract of an } 18 \text { to } 20 \text { per Cent. } \\
\text { Superphosphate }(1 \mathrm{Grm} \text {. of } \\
\text { material). }\end{array}$} & \multicolumn{3}{|c|}{$\begin{array}{c}\text { For } 100 \text { c.c. of a } 2 \text { per } \\
\text { Cent. Citric Acid Extract } \\
\text { of } 12 \text { to } 15 \text { per Cent. Thomas } \\
\text { Phosphate (1 Grm. of material) }\end{array}$} \\
\hline & & $\ldots$ & 75 c.c. & $\ldots$ & $\ldots$ & $\ldots$ & 100 c.c. \\
\hline Ammonia &, & $\ldots$ & 100 & $\ldots$ & $\ldots$ & $\ldots$ & 75 \\
\hline Magnesia & $"$ & $\ldots$ & 15 to 20 c.c. & $\ldots$ & $\ldots$ & $\ldots$ & 12 to 15 c.c. \\
\hline
\end{tabular}

